Int. J. Electrochem. Sci., 15 (2020) $2713-2726$

International Journal of

ELECTROCHEMICAL

SCIENCE

WwW.electrochemsci.org

\title{
Electrochemical Discharge Drilling of Inclined Micro Holes with Step Feeding Method
}

\author{
Hang Yusen, Xu Zhengyang*, Wang Feng, Zhang Chenxiang \\ National Key Laboratory of Science and Technology on Helicopter Transmission, Nanjing University \\ of Aeronautics and Astronautics, Nanjing 210016, China \\ *E-mail: xuzhy@nuaa.edu.cn
}

doi: $10.20964 / 2020.03 .13$

Received: 25 September 2019 / Accepted: 6 December 2019 / Published: 10 February 2020

Film cooling holes are distributed mainly on the surface of turbine blades, with center lines at angles to the tangential direction. These "inclined micro holes" (IMHs) are difficult to machine because of their extremely small diameters, the challenge of cutting metal materials, and the high requirements for machining quality/efficiency. To achieve machining of IMHs, we employed an electrochemical discharge drilling method. The recast layer, however, remained at the outlet of IMHs due to the turbulent flow field and short electrolysis time at the outlet. To improve further the processing quality of IMHs, step feedinging of electrode was used to prolong the electrolysis time (i.e., the tool electrode was stopped for a short time after penetrating the workpiece). Changing the feed rate and increasing the pause time of electrode (PToE) led to continuation of electrolysis after penetration of the electrode out of the IMH. Electrochemical dissolution around the IMH was sufficient to improve removal of the recast layer. Therefore, IMHs without a recast layer were obtained. Experiments with different PToE were carried out, and analyses of voltage waveforms, current waveforms, average diameter, IMH morphology, and elimination of the recast layer on IMH walls undertaken. Results showed that step feeding method could corrode the residual recast layer at the outlet of IMHs.

Keywords: Film cooling hole; Electrochemical machining (ECM); Electrical discharge machining (EDM); Electrochemical discharge drilling (ECDD); Inclined micro hole (IMH); Step feeding; Pause time of electrode (PToE); Recast layer

\section{FULL TEXT}

(C) 2020 The Authors. Published by ESG (www.electrochemsci.org). This article is an open access article distributed under the terms and conditions of the Creative Commons Attribution license (http://creativecommons.org/licenses/by/4.0/). 